\title{
Effectiveness of Improved Cookstoves to Reduce Indoor Air Pollution in Developing Countries. The Case of the Cassamance Natural Subregion, Western Africa
}

\author{
Candela de la Sota, Julio Lumbreras, Javier Mazorra*, Adolfo Narros, \\ Luz Fernández, Rafael Borge \\ Department of Chemical and Environmental Engineering, Technical University of Madrid (UPM), Spain \\ Email: "javimazorra@gmail.com
}

Received October 2013

\begin{abstract}
The Spanish NGO “Alianza por la Solidaridad” has installed improved cookstoves in 3000 households during 2012 and 2013 to improve energy efficiency reducing fuelwood consumption and to improve indoor air quality. The type of cookstoves were Noflaye Jeeg and Noflaye Jaboot and were installed in the Cassamance Natural Subregion covering part of Senegal, The Gambia and Guinea-Bissau. The Technical University of Madrid (UPM) has conducted a field study on a sample of these households to assess the effect of improved cookstoves on kitchen air quality. Measurements of carbon monoxide (CO) and fine particle matter $\left(\mathrm{PM}_{2.5}\right)$ were taken for 24-hr period before and after the installation of improved cookstoves. The 24-hr mean CO concentrations were lower than the World Health Organization (WHO) guidelines for Guinea-Bissau but higher for Senegal and Gambia, even after the installation of improved cookstoves. As for $\mathrm{PM}_{2.5}$ concentrations, 24-hr mean were always higher than these guidelines. However, improved cookstoves produced significant reductions on 24-hr mean $\mathrm{CO}$ and $\mathrm{PM}_{2.5}$ concentrations in Senegal and for mean and maximum $\mathrm{PM}_{2.5}$ concentration on Gambia. Although this variability needs to be explained by further research to determine which other factors could affect indoor air pollution, the study provided a better understanding of the problem and envisaged alternatives to be implemented in future phases of the NGO project.
\end{abstract}

Keywords: Indoor Air Pollution; Improved Cookstoves; Biomass Burning; Health Effects; Western Africa

\section{Introduction}

According to the International Energy Agency 2.7 billion people (40\% of global population) rely on the traditional use of biomass for cooking (IEA, 2010). The traditional use of biomass refers to the basic technology used, such as three-stone fire or inefficient cookstove, and not the resource itself.

As a result of the incomplete combustion due to inefficient conditions, many pollutants are emitted, both gaseous and solid or liquid. The major compounds are: carbon monoxide (CO), particulate matter $(\mathrm{PM})$, nitrogen dioxide $\left(\mathrm{NO}_{2}\right)$ and other organic compounds.

The exposure to these pollutants during long periods of time has a wide range of health effects causing around 1.5 million premature deaths per year worldwide, being the second leading cause of death in developing countries today and the first by 2030 (IEA, 2010).

Up to date, numerous studies have pointed out the relationship between the exposure to indoor air pollution (IAP) and several health problems (WHO, 2006). There is scientific evidence that risk of pneumonia and acute infection of the lower respiratory tract among children under five years old and risk of suffering from chronic obstructive pulmonary disease in adult women are bigger in households where wood or coal is used for cooking activities than in those where electricity, gas or other cleaner fuels are used (WHO, 2006). Other problems such as

\footnotetext{
*Corresponding author
}

eye diseases and burns are likewise extended.

In these households, pollutant levels can be between 10 and 50 times higher than the standard set by the World Health Organization (WHO) for CO and PM (shown in Table 1).

\section{Case Study}

The Casamance Natural Subregion in Western Africa is located between three countries: Senegal, The Gambia and Guinea-Bissau, forming an interdependent system with common geographical and ethnic characteristics. The subregion also shares a high level of poverty, analphabetism and malnutrition, which specially affect women.

This situation contrasts with the great potential of natural and productive resources. However, the unequal distribution of these resources produces several difficulties for the subregion inhabitants. Even more, the pressure over natural resources is increasing due to climate change and food-related products competence (for biofuel production, timber and other crops).

Within this context, the Spanish NGO "Alianza por la Solidaridad" is carrying out a 4-year project with the aim of contributing to poverty aleviation and improvement of living standards in the Casamance Natural Subregion and promoting food sovereignty and environmental governance.

Among several areas of work, there is one focused on the improvement of energy efficiency at both the family and the community sphere through the change from three-stone stoves 
Table 1.

WHO guidelines values set for pollutants.

\begin{tabular}{|c|c|c|}
\hline Pollutant & Observed effect & Guideline value \\
\hline $\mathrm{CO}^{*}$ & Decrease in exercise tolerance and increase symptoms in people with ischemic heart problems. & $\begin{array}{l}15 \mathrm{~min} . \text { mean }-100 \mathrm{mg} / \mathrm{m}^{3} \\
1 \mathrm{hr} . \text { mean-35 mg/m } \\
8 \mathrm{hr} \text {. mean-10 mg/m } \mathrm{m}^{3} \\
24 \mathrm{hr} . \text { mean }-7 \mathrm{mg} / \mathrm{m}^{3}\end{array}$ \\
\hline${ }^{* *} \mathrm{PM}$ & Effects on respiratory and cardiovascular systems. & 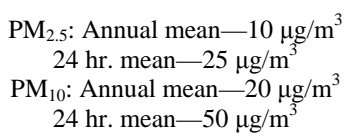 \\
\hline $\mathrm{NO}_{2}{ }^{*}$ & $\begin{array}{l}\text { Respiratory symptoms, bronchoconstriction, increased bronchial reactivity, } \\
\text { respiratory tract inflammation, increased susceptibility to respiratory inflammation. }\end{array}$ & $\begin{array}{l}\text { 1hr. Mean-200 } \mu \mathrm{g} / \mathrm{m}^{3} \\
\text { Annual mean }-40 \mu \mathrm{g} / \mathrm{m}^{3}\end{array}$ \\
\hline
\end{tabular}

Note: Source: (WHO, 2010) ${ }^{*}$ and (WHO, 2005) ${ }^{* *}$.

to improved cookstoves. The main aim of this activity is to achieve a reduction on fuelwood consumption, collection time and indoor air pollution related to the traditional use of biomass.

During 2012 and 2013, the work area was geographically limited to rural communities of Kerawane and Wassadou in Senegal, the Pirada Sector in Guinea-Bissau and Samba Sira District in The Gambia. After a participatory process, it was decided to install two improved cookstoves in each household, the Noflaye Jeeg and Noflaye Jaboot stoves (Figure 1). These stoves do not include a chimney and they are locally produced adapting the Rocket Stove model. During this period, improved cookstoves were installed in 3000 households.

\section{Methodology}

\section{Study Design}

Measurements presented in this study were obtained between January 2013 and March 2013 in households of 6 rural villages, two in each country, using a "before and after" design as it requires smallest sample size and it reduces variability because same households are used (Edwards, R. et al., 2007). In order to quantify seasonal effects independently from the impact of the improved cookstove is necessary to do a "before and after with control” design (Edwards, R. et al., 2007), but due to great variability in kitchen characteristics and ventilation and the necessity of larger sample, it was chosen to do the study without a control group (according to Dutta, K. et al., 2007). To avoid this problem, all the measurement, before and after the stove installation, were done during the same season and climatic conditions (Edwards, R. et al., 2007), in this case the dry season. Participating households were selected in cooperation with the local team and with previous information from the NGO. The number of household selected in each village is shown in Table 2.

\section{Indoor Air Pollution Monitoring}

IAP was determined by continuous measurements of carbon monoxide (CO) and fine particulate matter $\left(\mathrm{PM}_{2.5}\right)$ concentrations in each kitchen for a 24-hour period before and after the installation of the improved cookstoves.

Monitoring equipments were selected based on the following criteria: portability, autonomy and capability of long-time data storage. These characteristics are necessary to obtain valid re-
Table 2.

Number of participating household in each village.

\begin{tabular}{ccc}
\hline \multirow{2}{*}{ Village } & \multicolumn{2}{c}{$\mathbf{N}^{\circ}$ of Households } \\
\cline { 2 - 3 } & Before & After \\
\hline Colondito Fouta & 11 & 27 \\
Diyabougou & 22 & 22 \\
Sissaucunda Samanco & 11 & \\
Helacunda & 11 & 26 \\
& The Gambia & 11 \\
Brikama-Ba & 40 & 40 \\
Ker Ardo & 54 & 49 \\
\hline
\end{tabular}

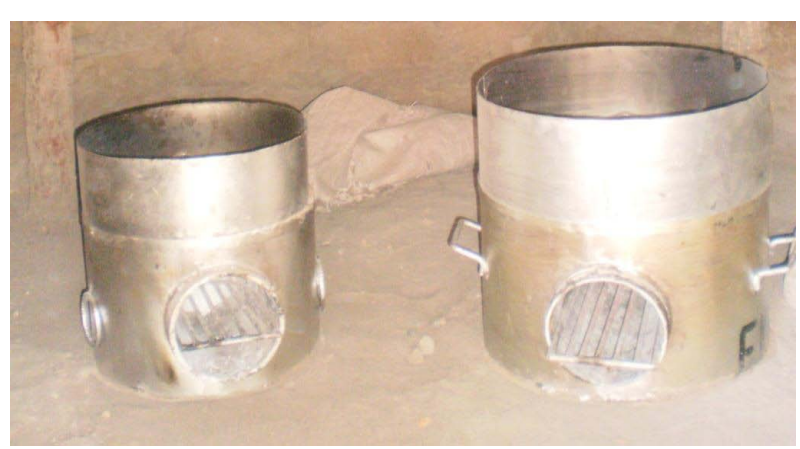

Figure 1.

Noflaye Jegg (left) and Noflaye Jaboot (rigth) stoves.

sults in this type of studies (Bates, L. et al., 2005; MacCarty, N. et al., 2008; Chowdury, Z. et al., 2012). According to this, CO measurements were made with the EL-USB-CO monitor (Lascar Electronics Ltd., UK), that uses an electrochemical sensor while $\mathrm{PM}_{2.5}$ was monitored with IAP Meter 5000 Series (Aprovecho Research Center, OR, USA) applying a light scattering technique. Both of them included a data logger to store minutal data during all the measurement period.

EL-USB-CO monitors were placed $1 \mathrm{~m}$ away from the com- 
bustion zone and $1.45 \mathrm{~m}$ high and IAP Meter 5000 Series monitors $1.3 \mathrm{~m}$ away from the combustion side and $1.3 \mathrm{~m}$ high, both on the side of the stove opposite to open doors and windows (Bates, L. et al., 2005; MacCarty, N. et al., 2008). Standard protocols were followed to perform each measurement (Bails, R. et al., 2007; Smith, K.R. et al., 2007).

\section{Household Questionnaires}

In each household selected for the study a survey was made by the field team before and after the stove change using a common questionnaire which was translated to every local language. People interviewed were women on charge of cooking activities and head of households.

The information collected was about social and economic factors, family characteristics, woodfuel use, stove use, cooking patterns and habits along with factors that could affect pollutants concentration during the measurement period.
Together with this questionnaire, physical data such as kitchen shape and size, ventilation, number and size of doors and windows, amount and size of woodfuel used, were taken.

\section{Results and discussion}

Pollutant concentrations, as 24-hr mean and maximum for $\mathrm{CO}$ and $\mathrm{PM}_{2.5}$, before and after the installation of improved cookstoves including the percent change for each village and the country average, are shown in Tables $\mathbf{3}$ and $\mathbf{4}$.

\section{CO Concentration}

CO measurements show that 24-hr mean concentrations are higher than WHO guideline values in Senegal and Gambia, and lower in Guinea-Bissau (except for Sissacunda Samanco before the installation).

Figures 2 and 3 show the graphical representation conclud-

Table 3.

24-hr mean and maximum CO concentration (ppm) before and after installation of improved cookstoves.

\begin{tabular}{|c|c|c|c|c|c|c|c|c|c|}
\hline & & \multicolumn{3}{|c|}{ Before } & \multicolumn{3}{|c|}{ After } & \multirow{2}{*}{$\begin{array}{c}\text { 24-hr mean } \\
\text { percent change }\end{array}$} & \multirow{2}{*}{$\begin{array}{l}\text { Maximum percent } \\
\text { change }\end{array}$} \\
\hline & & Mean & SD & Maximum & Mean & SD & Maximum & & \\
\hline \multirow{3}{*}{ Senegal } & Colondito Fouta & 16.00 & 11.56 & 170.00 & 9.04 & 7.04 & 149.78 & $-29.38^{* * *}$ & 7.14 \\
\hline & Diyabougou & 33.79 & 18.57 & 210.57 & 21.20 & 11.77 & 193.53 & $-37.26^{* *}$ & -8.09 \\
\hline & Average & 24.90 & 18.45 & 190.28 & 15.12 & 11.05 & 171.65 & $-33.32^{* *}$ & -0.48 \\
\hline \multirow{3}{*}{ Guinea-Bissau } & Sissaucunda Samanco & 8.98 & 4.14 & 95.77 & $6.60^{*}$ & 4.90 & 101.86 & -43.16 & -22.59 \\
\hline & Helacunda & $1.43^{*}$ & 1.87 & 48.23 & $0.77^{*}$ & 1.73 & 35.00 & -46.35 & -27.43 \\
\hline & Average & $5.21^{*}$ & 4.97 & 72.00 & $3.68^{*}$ & 3.92 & 68.43 & -46.35 & -27.43 \\
\hline \multirow{3}{*}{ The Gambia } & Ker Ardo & 14.9 & 8.91 & 191.38 & 12.63 & 11.27 & 179.09 & -15.24 & 16.10 \\
\hline & Brikama Ba & 15.69 & 10.79 & 169.7 & 13.26 & 10.54 & 197.06 & -15.48 & 6.86 \\
\hline & Average & 15.29 & 9.99 & 174.42 & 12.95 & 11.04 & 194.22 & -15.48 & 11.48 \\
\hline
\end{tabular}

Note: ${ }^{*}$ Lower than WHO guideline value. ${ }^{* *}$ Significant reduction $(p<0.05)$.

Table 4.

24-hr mean and maximum $\mathrm{PM}_{2.5}$ concentration $\left(\mu \mathrm{g} / \mathrm{m}^{3}\right.$ ) before and after installation of improved cookstoves.

\begin{tabular}{|c|c|c|c|c|c|c|c|c|c|}
\hline & & \multicolumn{3}{|c|}{ Before } & \multicolumn{3}{|c|}{ After } & \multirow{2}{*}{$\begin{array}{c}\text { 24-hr mean } \\
\text { percent change }\end{array}$} & \multirow{2}{*}{$\begin{array}{l}\text { Maximum percent } \\
\text { change }\end{array}$} \\
\hline & & Mean & SD & Maximum & Mean & SD & Maximum & & \\
\hline \multirow{3}{*}{ Senegal } & Colondito Fouta & 1010 & - & 66091.00 & 241.67 & 170.6 & 34478.78 & $-39.60^{* *}$ & -36.06 \\
\hline & Diyabougou & 809.50 & 404.7 & 42321.10 & 531.7 & 333.7 & 54269.22 & $-34.32^{* *}$ & 28.23 \\
\hline & Average & 909.75 & 388.6 & 54206.05 & 386.67 & 293.4 & 44374.00 & $-36.96^{* *}$ & -3.91 \\
\hline \multirow{3}{*}{ Guinea-Bissau } & Sissaucunda Samanco & 207.5 & 96.9 & 34566.50 & 182.00 & 180.5 & 46185.00 & 133.49 & 93.93 \\
\hline & Helacunda & 62.00 & 1.4 & 6937.00 & 57.10 & 71.2 & 8965.40 & -30.65 & -8.15 \\
\hline & Average & 134.75 & 107.9 & 20751.75 & 119.55 & 148.1 & 27575.20 & 51.42 & 42.89 \\
\hline \multirow{3}{*}{ The Gambia } & Ker Ardo & 725.50 & 485.1 & 74223.50 & 288.20 & 289.8 & 43919.60 & $-60.28^{* *}$ & $-40.83^{* *}$ \\
\hline & Brikama Ba & 439.30 & 333.7 & 45946.70 & 415.6 & 312.0 & 39264.80 & -5.39 & -14.54 \\
\hline & Average & 582.40 & 431.0 & 60085.10 & 351.90 & 300.3 & 41592.20 & -32.84 & -27.69 \\
\hline
\end{tabular}

Note: ${ }^{*}$ Lower than WHO guideline value. ${ }^{* *}$ Significant reduction $(p<0.05)$. 


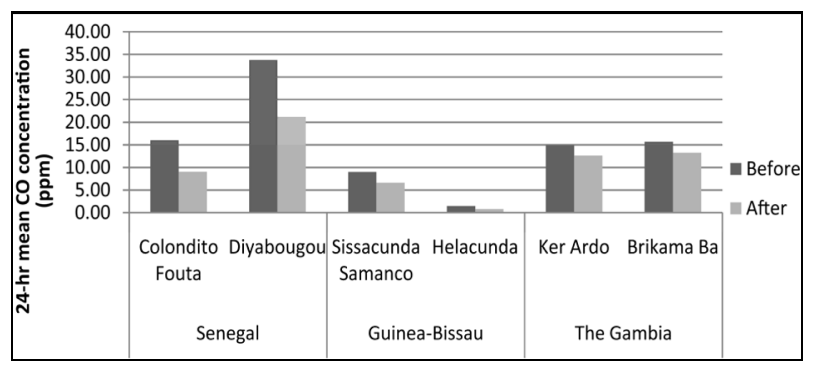

Figure 2.

24-hour mean CO concentrations before and after the instalattion of the improved cookstove in each village.

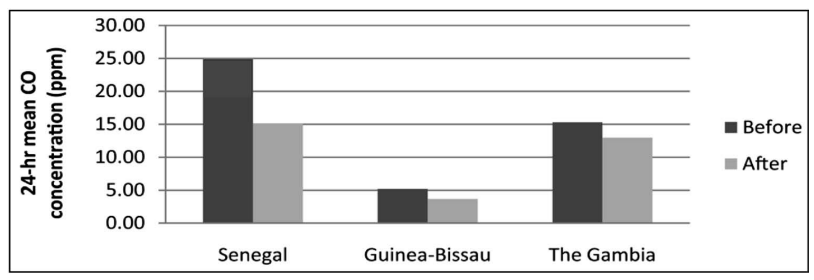

Figure 3.

24-hour mean CO concentrations before and after the instalattion of the improved cookstove country averages.

ing that:

- The highest 24-hr mean CO concentration was observed in Diyabougou. This result could be explained by the higher wood consumption due to a higher family size.

- The lowest 24-hr mean CO concentration was obtained in Guinea-Bissau due to a better kitchen ventilation

- There are no significant differences between Colondito Fouta with Gambians villages.

- The lowest maximum concentrations were observed in Guinea-Bissau while no differences between Gambia and Senegal were identified.

Concerning CO concentration variations between before and after:

- A significant reduction $(p<0.05)$ for 24 -hr mean CO concentration was observed in Senegal although they are not enough to accomplish with WHO guideline values.

- In Guinea-Bissau, the highest reductions in percentage of 24-hr mean CO concentration were measured although these reductions are low in absolute terms with no statistical significance.

- In Gambia, where 24-hr mean CO concentration were similar to Senegal, a lower reduction was obtained and with no statistical significance.

- A great variability on maximum concentrations was observed with no significant reduction anywhere.

\section{$\mathbf{P M}_{2.5}$ Concentration}

$\mathrm{PM}_{2.5}$ measurements showed that 24-hr mean concentrations are higher than WHO guideline values in all villages and countries.

Graphical representation of results (Figures 4 and 5), shows:

- 24-hr mean $\mathrm{PM}_{2.5}$ concentrations were bigger in Senegal than in the other countries. It was also observed that Diyabougou have a similar result to Colondito Fouta, contrarily to 24-hr mean CO values.

- In Guinea-Bissau, 24-hr mean $\mathrm{PM}_{2.5}$ concentrations were

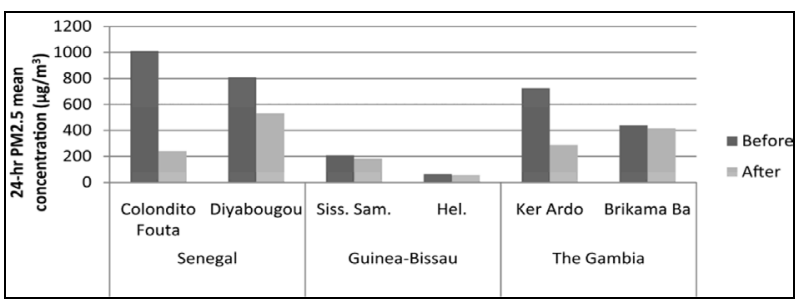

Figure 4.

24-hour mean $\mathrm{PM}_{2.5}$ concentrations before and after the instalattion of the improved cookstove in each village.

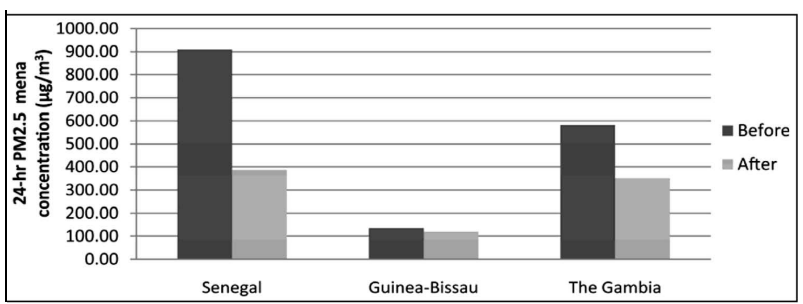

Figure 5.

24-hour mean $\mathrm{PM}_{2.5}$ concentrations before and after the instalattion of the improved cookstove country average.

lower than in other villages and countries, as occurred for 24-hr mean CO values due to higher ventilations.

- In Gambia, results showed that concentration in Ker Ardo was quite bigger than in Brikama Ba before the installation but with improved cookstoves, results were the opposite.

- The maximum concentration before installation was observed in Ker Ardo maybe linked to the use of alternative fuels as plastics or crop and livestock wastes due the wood fuel scarcity.

- In Helacunda maximum concentration was lower because in this village is usual to cook outside during the dry season.

In Table 4, changes between before and after the installation showed a great variability within three countries:

- As in the case of CO concentration, a significant reduction $(p<0.05)$ is observed for 24-hr mean $\mathrm{PM}_{2.5}$ concentration in Senegal although they are not enough to accomplish with WHO guidelines.

- In Guinea-Bissau, reductions were not statistically significant.

- In Gambia, a significant reduction $(p<0.05)$ was found for 24-hr mean $\mathrm{PM}_{2.5}$ concentration in Ker Ardo but no significance was observed for Brikama Ba. Ker Ardo results could be explained by the reduction in the use of alternative fuels with improved cookstoves.

- In Ker Ardo, a significant reduction $(p<0.05)$ for the maximum $\mathrm{PM}_{2.5}$ concentration was also identified.

- In other villages, maximum concentrations did not show significant reductions.

\section{Conclusion}

Concerning potential health problems associated to 24-hr mean CO concentrations, only Guinea-Bissau values were lower than the WHO guidelines, both before and after the cookstove implementation. For Senegal and Gambia, concentrations were higher, even using improved cookstoves. As for 24-hr 
mean $\mathrm{PM}_{2.5}$ concentrations, they were higher than WHO guidelines for all cases.

Improved cookstoves installation produced significant reduction in Senegal for 24-hr mean CO and $\mathrm{PM}_{2.5}$ concentration and in one of the Gambia's locations for 24-hr mean and maximum $\mathrm{PM}_{2.5}$ concentration. However, no significant reductions were observed for Guinea Bissau. This variability is usual in programs implementing improved cookstoves without chimney.

Although the same stoves are used in each village, it has been obtained a wide range of results. Further research is needed to determine which other factors could affect pollutant concentration inside kitchens as type of fuel used for cooking, woodfuel consumption, kitchen shape and size, and ventilation.

\section{REFERENCES}

Bailis, R., Berrueta, V., Chengappa, C., Dutta, K., Edwards, R., Masera, O. et al. (2007). Performance testing for monitoring improved biomass stove interventions: Experiences of the Household Energy and Health Project. Energy for Sustainable Development, 11, 57-70. http://dx.doi.org/10.1016/S0973-0826(08)60400-7

Bates, L., Bruce, N., Theuri, D., Owala, H., Hada, J., Hood, A. et al. (2005). Smoke, health and household energy. Volume 1: Participatory methods for design, installation, monitoring and assessment of smoke alleviation technologies. ITDG/Practical Action.

Chowdury, Z., Le, L. T., Al Masud, A., Chang, K. C., Alauddin, M., Hossain, M. et al. (2012). Quantification of indoor air pollution from using cookstoves and estimation of its health effects on adult women in northwest Bangladesh. Aerosol and Air Quality Research, 12, 463475.

Dutta, K., Shields, N. K., Edwards, R., \& Smith, K. R. (2007). Impact of improved biomass cookstoves on indoor air quality near Pune, India. Energy for Sustainable Development, 11, 19-32. http://dx.doi.org/10.1016/S0973-0826(08)60397-X

Edwards, R., Hubbard, A., Khalakdina, A., Pennise, D., \& Smith, K. R. (2007). Design considerations for field studies of changes in indoor air pollution due to improved stoves. Energy for Sustainable Development, 11, 71-81.

http://dx.doi.org/10.1016/S0973-0826(08)60401-9

IEA (2010). World energy outlook 2010, energy poverty. How to make modern energy access universal? International Energy Agency.

MacCarty, N., Still, D., Ogle, D., \& Drouin, T. (2008). Assessing cook stove performance: Field and lab studies of three rocket stoves comparing the open fire and traditional stoves in tamil nadu, india on measures of time to cook, fuel use, total emissions, and indoor air pollution. Aprovecho Research Center.

Smith, K. R., Dutta, K., Chengappa, C., Gusain, P. P. S., Masera, O., Berrueta, V. et al. (2007). Monitoring and evaluation of improved biomass cookstove programs for indoor air quality and stove performance: conclusions from the Household Energy and Health Project. Energy for Sustainable Development, 11, 5-18. http://dx.doi.org/10.1016/S0973-0826(08)60396-8

WHO (2005). Air Quality guidelines global update 2005. World Health Organization.

WHO (2006). Fuel for life. Household energy and health. World Health Organization.

WHO (2010). WHO guidelines for indoor air quality: Selected pollutants. World Health Organization. 